Научная статья

УДК 327.33 (470:520), 94(470), 94(520).033.55

DOI 10.18101/2306-630X-2020-2-3-9

\title{
ЗНАЧЕНИЕ И РОЛЬ ГОРОДОВ-ПОБРАТИМОВ В РАЗВИТИИ РУССКО-ЯПОНСКОЙ МЕЖКУЛЬТУРНОЙ КОММУНИКАЦИИ
}

\author{
(C) Гавриков Алексей Александрович \\ кандидат исторических наук, \\ Иркутский государственный университет \\ Россия, 664011, г. Иркутск, ул. Нижняя Набережная, 6 \\ agav2008@mail.ru
}

\begin{abstract}
Аннотация. Развитие дружественных связей между городами-побратимами как одна из форм гражданской дипломатии в значительной мере способствует укреплению русско-японской межкультурной коммуникации. Преимуществом гражданской дипломатии является абстрагирование от политических и дипломатических проблем в налаживании дружественных отношений между народами России и Японии. Это особенно важно на современном этапе развития русско-японских отношений, когда нередко предлогом для их ухудшения выступают отсутствие мирного договора и проблема «Северных территорий». Следует обратить внимание и на то, что развитие побратимских связей между городами Японии и России не должно ограничиваться сферами культуры и спорта - тесное взаимодействие в научных сферах, таких как, например, экология, медицина, не менее актуально в условиях современной действительности. Обмен передовым опытом в указанных научных сферах способствует не только укреплению связей между городами-побратимами, но и улучшению качества жизни и повышению уровня благосостояния населения городов в России и Японии.
\end{abstract}

Ключевые слова: русско-японские отношения; межкультурная коммуникация; города-побратимы; гражданская дипломатия.

\section{Для цитирования}

Гавриков A. A. Значение и роль городов-побратимов в развитии русско-японской межкультурной коммуникации // Евразийство и мир. 2020. № 2. С. 3-9.

В исторической науке зарождение движения по установлению побратимских связей между городами различных государств (движения породненных городов) связывают с породнением английского города Ковентри и находящегося в крайне тяжелом положении Сталинграда 10 июня 1944 г.

Во второй половине XX - начале XXI в. становление побратимских связей между городами стало одной из распространенных форм гражданской (народной) дипломатии. Принятая на вооружение и поддержанная американским президентом Д. Эйзенхауэром в первое послевоенное десятилетие идея породнения городов, имеющих общность по историческим, социокультурным, политическим, географическим признакам, получила в дальнейшем широкое распространение во всем мире.

28 апреля 1957 г. в городе Экс-ле-Бен (Франция) была создана Всемирная федерация породненных городов. К началу XXI в. она объединила свыше 3500 городов более чем 160 стран, в их числе свыше 50 российских и японских городов. Роднятся, 
как правило, города, имеющие схожие исторические судьбы, административное устройство, географическое положение. Так, например, расположенные в префектуре Исикава в 20 километрах друг от друга столица префектуры город Канадзава и город Номи (до 2005 г. - Нэагари (Ниагари, Неагари)) являются побратимами центра Иркутской области города Иркутска и расположенного в 20 километрах от него города Шелехова ${ }^{1}$. При этом даже количество населения обеих пар городов приблизительно совпадает. Сходство географических и статистических данных (количество населения, площадь занимаемой территории) роднит столицу Республики Бурятия Улан-Удэ с японским городом Ямагата ${ }^{2}$, столицей одноименной префектуры.

Исходя из определения, данного исследователем Т. И. Медведевой, гражданская дипломатия, развивающаяся в демократических государствах, в противовес народной дипломатии, существующей в государствах авторитарного типа, — «это неофициальная как внешнеполитическая, так и внутриполитическая деятельность не зависимых непосредственно от правительств физических и юридических лиц, неправительственных организаций (НПО), движений и институтов, направленная на сохранение мира, развитие и улучшение межгосударственных отношений, на развитие дружбы, взаимопонимания и сотрудничества между разными народами» [1, с. 12]. Таким образом, можно утверждать, что побратимские отношения между городами Японии и СССР строились в рамках народной дипломатии, а отношения между городами Российской Федерации и Японии, двух демократических государств,- - рамках гражданской дипломатии.

Как правило, в обоих государствах развитие побратимских связей между городами поддерживается акторами реалистического направления гражданской дипломатии (неправительственными организациями, общественными движениями, юридическими и физическими лицами) [там же, с. 15], выступающими за налаживание взаимовыгодных партнерских отношений между Россией и Японией.

Весьма интересен факт, что во все времена, начиная с 1961 г., когда породнились первые города Советского Союза и Японии (г. Находка — г. Мэйдзуру, 21 июня 1961 г.), инициатива народной, а позднее гражданской, дипломатии по установлению и развитию побратимских связей всегда находила поддержку у местных, региональных и государственных властей. Члены правительств обоих государств видели и продолжают видеть в ней один из путей налаживания дружественных отношений между Японией и Россией, минуя необходимость решения территориального спора из-за «Северных территорий». Так, на официальном сайте посольства Японии в России еще совсем недавно сообщалось следующее: «При наличии у российских субъектов местного самоуправления желания установить побратимские связи с субъектами местного самоуправления в Японии посольство Японии предпринимает следующие действия в поддержку данного начинания». Далее излагались алгоритмы действий посольства по поддержанию инициативы по установлению побратимских связей со стороны администраций российских городов, а также сведения о том, какую информацию

\footnotetext{
${ }^{1}$ Официальный сайт администрации Шелеховского района [Электронный ресурс]. URL: http://www.sheladm.ru/qa/60.2.html (дата обращения: 01.04.2017).

2 Город Улан-Удэ породнен с двумя японскими городами: с Румои (с 1972 г.) и с Ямагата (с 1991 г.).
} 
Гавриков А. А. Значение и роль городов-побратимов в развитии русско-японской межкультурной коммуникации

о себе должен представить город, желающий обрести японского побратима ${ }^{1}$. К слову, ссылка, приведенная в списке источников, действительна и по состоянию на ноябрь 2020 г., но прямого перехода на нее со страницы «Японо-российские отношения» уже нет. Вместо этого на сайте в виде отдельного документа, предназначенного для скачивания, помещен список городов-побратимов ${ }^{2}$.

Сотрудничество на уровне субъектов местного самоуправления организовано в самых различных областях культуры, спорта, науки, искусства, в социальной сфере, в промышленности. Особо важно отметить, что культурное и деловое сотрудничество городов-побратимов России и Японии играет значительную роль в создании положительного имиджа (образа) страны-соседа в глазах российского и японского общества. Исследователи В.Э. Молодяков и А. Е. Куланов обращают внимание на то, что «пути формирования имиджа страны многообразны. Его возникновение немыслимо без непосредственных контактов, но они не обязательны для каждого носителя образа. Основные виды контактов - пребывание представителей страны-"образотворца" в стране-"предмете образа", и наоборот, то есть "наши за границей" и "иностранцы у нас" всегда являются прерогативой меньшинства, особенно в условиях географической отдаленности, культурных различий, политической напряженности» [2, с. 19]. Однако вторая половина данного утверждения была справедлива для дореволюционного и советского периода русско-японских отношений. В постсоветский период регулярный обмен делегациями (школьников, студентов, ученых, сотрудников предприятий и учреждений), развитие туризма между городами-побратимами России и Японии в значительной степени способствуют тому, что «непосредственные контакты» перестают быть «прерогативой меньшинства». На общем фоне развития русско-японских межкультурных связей активизация деятельности акторов гражданской дипломатии в 1990-х гг. и в последующий период привела к тому, что «японская культура, проникавшая в нашу страну в эпоху СССР и хлынувшая неудержимым потоком сейчас, становится привычной. Российская публика... сегодня со всей серьезностью обсуждает нюансы театра кабуки, а некоторые околояпонистические круги всерьез разговаривают и о но» [там же, с. 424].

В условиях глобализации, развития современных технологий значительно облегчается налаживание межкультурного обмена между Японией и находящимися, например, в европейской части России городами, однако все равно сохраняется определенный дисбаланс в породнении российских и японских городов. Так, все крупные города Дальнего Востока России (Хабаровск, Владивосток, Южно-Сахалинск, Находка) имеют, как правило, по несколько городов-побратимов в Японии. Большинство крупных городов Сибири и Забайкалья (Новосибирск, Иркутск, Улан-Удэ, Якутск) породнены каждый с одним-двумя японскими городами. В европейской же части России почти нет городов, имеющих японских побратимов. По состоянию на конец 2016 г., когда состоялся официальный визит в Японию Президента Рос-

\footnotetext{
${ }^{1}$ Города-побратимы // Официальный сайт Посольства Японии в России [Электронный реcypc]. URL: http://www.ru.emb-japan.go.jp/RELATIONSHIP/TWINCITIES/ (дата обращения: 01.04.2017).

2 Японо-российские отношения // Официальный сайт Посольства Японии в России [Электронный ресурc]. URL: https://www.ru.emb-japan.go.jp/RELATIONSHIP/ (дата обращения: 20.11.2020).
} 
сийской Федерации В. В. Путина, побратимы здесь были только у Волгограда, Кронштадта, Санкт-Петербурга и Москвы. При этом следует отметить, что в ряде случаев побратимские связи городов европейской части нашей страны с японскими городами весьма символичны. Так, символично, что побратимами являются наиболее пострадавшие в годы Второй мировой войны города - Волгоград и Хиросима (с 28 сентября 1972 г.). Символично и то, что столицы обоих государств-Москва и Токио - также являются побратимами (с 16 июля 1991 г.).

На фоне весьма активного сотрудничества сибирских и дальневосточных российских городов с японскими побратимами подобное взаимодействие на территории Европейской России (именно в рамках побратимских связей) выглядит менее интенсивным и разнообразным. По признанию губернатора Токио госпожи Юрико Коикэ, сотрудничество между нашими столицами активно развивается преимущественно в области спорта: «В частности, каждый год на Токийский международный чемпионат по юношескому футболу приезжают команды из российской столицы» ${ }^{2}$. При этом госпожа Юрико обратила внимание на то, что «основные общие проблемы Токио и Москвы - вопросы переработки отходов и пробки на дорогах», и, как следствие, сотрудничество между двумя мегаполисами, направленное на решение этих проблем, имеет значительные перспективы² ${ }^{2}$

В конце 2016 г. визит Президента Российской Федерации В. В. Путина в Японию вызвал определенное оживление в русско-японских отношениях. Средства массовой информации и в России, и в Японии запестрели новостями. Одной из таких новостей стало опубликованное 16 декабря 2016 г. «Российской газетой» известие о том, что администрация города Сочи приняла приглашение японского города Нагато к установлению побратимских связей и «к сотрудничеству с Нагато по направлениям туризма, культуры, спорта и образования» ${ }^{3}$. Итогом переговоров и обмена делегациями стало подписание 28 сентября 2018 г. соглашения об установлении дружественных отношений между городом Сочи и городом Нагато ${ }^{4}$.

Отношения на уровне субъектов местного самоуправления в рамках дружеских связей между городами-побратимами России и Японии, как уже упоминалось, наиболее интенсивно развиваются в Дальневосточном регионе и в Восточной Сибири. Расширяются и поддерживаются связи в области образования, культуры, спорта и промышленности. Ярким примером здесь служат отношения Иркутска и Канадзава: «С 1967 г. началось тесное сотрудничество... в разных областях деятельности. Открывается "Дом дружбы" (в Иркутске. - А. Г.), проводятся первые курсы изучения японского языка, начинаются обмены официальными, спортивными делегациями, улица в центре города Иркутска получает название «улица Канадзава».

\footnotetext{
${ }^{1}$ Юрико Коикэ: Города-побратимы Москва и Токио продолжат активное развитие отношений. Беседовал корр. ТАСС в Токио Игорь Беляев [Электронный ресурс]. URL: http://tass. ru/opinions/interviews/3639616 (дата обращения: 01.04.2017).

2 Там же.

${ }^{3}$ Бондаренко О. Сочи и японский Нагато станут побратимами // Российская газета. 2016.16.12.

${ }^{4}$ Официальный портал города-курорта Сочи [Электронный ресурс]. URL: https://sochi.ru/ gorod/vnesh-svyazi/goroda-pobratimy/nagato/ (дата обращения: 20.11.2020).
} 
Гавриков А. А. Значение и роль городов-побратимов в развитии русско-японской межкультурной коммуникации

В дни празднования 30-летия побратимских отношений в Иркутске был открыт памятный знак города Канадзава - фонарь «Котодзиторо» ${ }^{1}$. Весьма интенсивно развиваются связи между учебными заведениями Иркутска и Канадзавы: регулярно осуществляются обмены школьниками, студентами, педагогическими работниками и специалистами из разных научных областей. «В городе Иркутске поддерживают и развивают сотрудничество несколько клубов русско-японской дружбы "Кенроку", "Асахи", "Гиппо-клуб", "Икебана", проводятся заседания Ассоциации преподавателей японского языка. С 16 сентября 2003 года в городе Иркутске в спорткомплексе "Октябрьский" Байкальского государственного университета экономики и права начал работу клуб "Кендо"... В настоящий момент японский язык преподают в пяти вузах г. Иркутска ${ }^{2}$. Кроме того, для всех желающих ближе познакомиться с культурой, историей Японии открывает свои двери Японский информационный центр, единственный в Восточной Сибири, функционирующий с 2002 г.

Не менее активными и тесными являются дружественные связи столицы Бурятии с японскими побратимами. В сентябре 2016 г. в связи с празднованием 350-летия основания города Улан-Удэ туда прибыла японская делегация во главе с мэром города Ямагата Такахиро Сато ${ }^{3}$. А уже вскоре после этого, 19 февраля 2017 г., в связи с празднованием 25-летия установления дружественных связей между двумя городами, на торжественной церемонии в Японии присутствовала русская делегация во главе с мэром города Улан-Удэ А. М. Голковым, которому «было присвоено высокое звание почетного гражданина города Ямагата» ${ }^{4}$.

Регулярно осуществляются обмены делегациями между малыми городамипобратимами Шелеховом и Номи: «За прошедшие годы (с 1988. - A. Г.) Страну восходящего солнца посетило около 900 человек и столько же японских гостей побывало в городе Шелехов» ${ }^{5}$. За годы сотрудничества в социальной, культурной и других сферах обоих городов появились даже устойчивые традиции, символизирующие родственные отношения: «Так, появилась традиция ежегодно во время визитов в Шелехов оставлять свои фото и подписи в "Золотой книге дружбы", высаживать деревья на аллее дружбы в детском саду "Подснежник", обязательно посещать место захоронения части праха господина Мори Сигеки и госпожи Мори Акико» ${ }^{6}$. Подобно тому как в Иркутске есть улица Канадзава, в Шелехове «есть сквер

\footnotetext{
${ }^{1}$ Города-побратимы Иркутска // Сайт МБУК г. Иркутска «Централизованная библиотечная система» [Электронный ресурс]. URL: http://cbs.irkipedia.ru/goroda-pobratimyi-irkutska/ (дата обращения: 01.04.2017).

${ }^{2}$ Города-побратимы Иркутска // Сайт МБУК г. Иркутска «Централизованная библиотечная система» [Электронный ресурс]. URL: http://cbs.irkipedia.ru/goroda-pobratimyi-irkutska/ (дата обращения: 01.04.2017).

${ }^{3}$ В Улан-Удэ встретили делегацию из Японии // Байкал Daily [Электронный pecypc]. URL: https://www.baikal-daily.ru/news/16/217032/ (дата обращения: 01.04.2017).

${ }_{4}^{4}$ Мэр Улан-Удэ получил в японской Ямагате звание почетного гражданина // Байкал Daily [Электронный ресурс]. URL: https:/www.baikal-daily.ru/news/19/236596/ (дата обращения: 01.04.2017).

${ }_{5}^{5}$ Официальный сайт администрации Шелеховского района [Электронный ресурc]. URL: http://www.sheladm.ru/qa/60.2.html (дата обращения: 01.04.2017).

6 Частицы праха мэра Нэагари господина Мори Сигэки (в 1990 г.) и его супруги госпожи Мори Акико (в 2010 г.) были захоронены на городском кладбище г. Шелехова в знак дружбы городов.
} 
Нэагари. История отношений городов Шелехов - Нэагари отражена в экспозициях городского музея Г. И. Шелехова. В центре развития творчества детей и юношества работает музей Мори Сигеки» ${ }^{1}$.

Русско-японские межкультурные связи городов-побратимов Дальневосточного региона, разумеется, развиваются еще более интенсивно. Так, деятельность российских дальневосточных вузов не ограничивается обменом студентами и преподавателями с вузами японских городов-побратимов. В частности, ДВГУ (ныне ДВФУ, г. Владивосток) в 1994 г. открыл в Хакодатэ свой филиал, единственный в Японии филиал российского вуза, на который «распространяется существующая в Японии программа "кодо-сэнмонси", т.е. "среднее специальное образование повышенного уровня", согласно которой человек, прошедший четырехлетний курс обучения в колледже, приравнивается к выпускнику вуза и может поступать в аспирантуру»².

В целом движение породнения городов уже давно не носит хаотического характера. Сотни российских городов, имеющих побратимов в разных странах мира, входят в состав международной ассоциации «Породненные города», которая, в свою очередь, действует под эгидой Всемирной организации «Объединенные города и местные власти», возникшей в 2004 г. путем слияния Всемирной федерации породненных городов и Международного союза местных властей. При этом в рамках движения породнения городов регулярно проходят различные конференции, форумы в разных городах мира. Один из крупнейших международных форумов ежегодно, начиная с 2014 г., проводится в Волгограде 31 октября (этот день объявлен Генеральной Ассамблеей ООН Всемирным днем городов). В форуме принимают участие отдельные представители и целые делегации из разных стран мира, в том числе и из Японии. В частности, японская делегация принимала участие во II Международном форуме «Политические решения и устойчивое развитие территорий» ${ }^{3}$.

Развитие туризма, гастроли театров, выставки живописи и предметов искусства, фотовыставки, обмен делегациями в рамках побратимских связей значительно укрепляют взаимное познание и взаимоуважение народов России и Японии и способствуют укреплению русско-японских отношений. Для многих крупных городов России, в частности городов Урала и европейской части нашей страны, открыты возможности обрести побратимов в лице японских городов. Так, например, все основания стать побратимами Екатеринбурга и Челябинска есть у таких промышленных центров Японии, как Китакюсю (префектура Фукуока) или Фукуяма (префектура Хиросима).

В условиях современной реальности, кроме того, представляется весьма продуктивным сотрудничество в области медицины. К сожалению, вводимые повсеместно карантинные ограничения не позволяют осуществлять обмен делегациями врачей, но уровень развития современных технологий вполне позволяет проводить

${ }^{1}$ Официальный сайт администрации Шелеховского района [Электронный ресурc]. URL: http://www.sheladm.ru/qa/60.2.html (дата обращения: 01.04.2017).

${ }^{2} 20$ лет филиалу ДВФУ в Хакодатэ. Интервью с директором Филиала Ильиным С. Н. [Электронный ресурc]. URL: http://www.jp-club.ru/20-let-filialu-dvfu-v-xakodate/ (дата обращения: 20.11.2020).

${ }^{3}$ Официальный сайт Международной ассоциации «Породненные Города» [Электронный pecypc]. URL: http://goroda-pobratimy.ru/publ/poslednie_novosti/ii_mezhdunarodnyj_forum_ gorodov_pobratimov_v_volgograde/1-1-0-155 (дата обращения: 01.04.2017). 
Гавриков A. А. Значение и роль городов-побратимов в развитии русско-японской межкультурной коммуникации

видеоконференции и взаимные консультации с целью обмена опытом и повышения квалификации медицинского персонала.

Таким образом, тесное русско-японское сотрудничество в рамках международного движения породненных городов имеет значительные перспективы во многих сферах жизнедеятельности российского и японского общества. К тому же совершенствование технологий открывает в наши дни акторам гражданской дипломатии значительные возможности для развития и углубления отношений. Преимущество данной формы сотрудничества как составной части межкультурной коммуникации заключается, прежде всего, в его аполитичности и абстрагировании от нерешенной (по мнению японской стороны и ряда отечественных «японофилов») территориальной проблемы.

\title{
Литература
}

1. Медведева Т. И. Гражданская (народная) дипломатия и ее роль в российско-японском политическом диалоге: автореф. дис. ... канд. пед. наук: специальность: 23.00.04 Политические проблемы международных отношений и глобального развития. М., 2007. 25 с.

2. Куланов А. Е., Молодяков В. Э. Россия и Япония: имиджевые войны. М., 2007. 480 с.

\section{CONTRIBUTION AND ROLE OF SISTER CITIES IN THE DEVELOPMENT OF RUSSIAN-JAPANESE INTERCULTURAL COMMUNICATION}

\author{
Alexey A. Gavrikov \\ Cand. Sci. (Hist.), Lecturer of History and Methodology Department, \\ Teacher's Training Institute of Irkutsk State University \\ 6 Niznyaya Naberezhnaya, Irkutsk 664011, Russia \\ agav2008@mail.ru
}

Abstract. Development of friendly ties between sister cities as one of the forms of civil diplomacy greatly contributes to the strengthening of Russian-Japanese intercultural communication. The advantage of civil diplomacy is the abstraction from political and diplomatic problems in the establishment of friendly relations between the peoples of Russia and Japan. This is especially important at the present stage, when the absence of a peace treaty and problem of the "Northern Territories" are often the pretext for the deterioration of Russian-Chinese relations. It is noted that the development of sister-city arrangement between the cities of Japan and Russia should not be limited to the spheres of culture and sports, close interaction in scientific fields, such as ecology, medicine is no less important in the conditions of modern reality. The exchange of best practices in these scientific fields contributes not only to the strengthening of ties between sister cities, but also to the improvement of living standards and well-being of the population in cities of Russia and Japan.

Keywords: Russian-Japanese relations; intercultural communication; sister cities; civil diplomacy.

Статья поступила в редакцию 23.11.2020; одобрена после рецензирования 07.12.2020; принята к публикации 11.12.2020. 